\title{
Ethno-Edible Mushroom of Pleurotus sp., Clytocybe nebularis and Auricularia auricula in Ranupani Village, East Java
}

\author{
Jehan Ramdani Haryati ${ }^{1 *}$ and Rodiyati Azrianingsih ${ }^{1}$ \\ ${ }^{1}$ Biology Department, Faculty of Mathematics and Sciences, Brawijaya University, Malang, Indonesia
}

\begin{abstract}
This paper documented the knowledge about the wild edible fungal flora of Ranupani Village of East Java Indonesia that used by indigenous Tenggerese tribes. Study was conducted by using semistructured interview and purposive sampling. Data were analyzed quantitatively descriptive. Index of Cultural Significance (ICS) was used to evaluate the importance of non-wood forest's yields for local people. Identification of edible mushrooms was based on Guidelines of Flora Diversity Data Collection. This study was focus on the three edible mushrooms which are eaten mostly by the villagers, i.e. Pleurotus sp., Clytocybe nebularis and Auricularia auricula. The result is the Ranupani residents' perception of edible mushrooms and its potential as an alternative source of food based on local knowledge and local wisdom of Tenggerese. Pleurotus sp. has the highest preference and intensity to be consumed with 3,2 ICS. It means culturally, this edible mushroom were not too important but intensively used as a secondary food sources such as soup (added or sauted), chips (dried) and fried. Ranupani Villagers always consumed edible mushrooms in rainy season. The ability of residents to distinguish edible mushrooms are equal to the searching ability to find edible mushroom substrate. The residents will recognized the substrate of edible mushrooms on dead trunks of Pasang Tree (Lithocarpus sundaicus), Danglu (Engelhardia spicata), Kemlandingan (Albiz̨ia Montana), Casuarina (Casuarina junghubniana) and acacia (Acacia decurens). Residents who do not have the ability to distinguish and searching were consumer, get the edible mushrooms by buying from the searcher or distributor in packs. The characteristics of an edible mushrooms are a discrete soft flesh of the fruit body, dark color, no ring on the stipe, the presence of insects (e.g. moths) in the lamellae) and the type of mushroom substrate. There were also assisted growths of wild mushrooms by the residents' raw chop the dead tree trunk as a substrate deliberately. Respondents who knew the time of harvesting edible mushroom were $58.3 \%$. Pasang mushrooms (natural \& assisted growth) can be found throughout the rainy season, with an interval of 12 days for subsequent retrieval. While Barat and Kuping mushrooms are found throughout the rainy season, but randomly distributed in the forest. There were unwritten but spoken hereditary local wisdom for the sustainable of the edible mushrooms in Tengger. Only Tenggerese allowed collecting and selling the edible mushrooms in Tengger area to the Tenggerese themselves and tourist (local or foreign). This wisdom is supported by TNBTS regulation that the edible mushroom were not allowed exported out of TNBTS area. This wisdom expectedly makes sure that the edible mushrooms should be sustained in the forest.
\end{abstract}

Keywords: Ethno-edible mushrooms, Ranupani

\section{INTRODUCTION}

Wild mushrooms tend to grow on area with high humidity and water available. Rainy season is the most proper time for mushrooms collections. Mushrooms could appear anywhere in any forest's detritus but exact growth time was

* Corresponding address:

Jehan Ramdani $\mathrm{H}$

Biology Department, Faculty of Mathematics and Sciences, Brawijaya University, Jl. Veteran, Malang, Indonesia 65145 jehanramdani@gmail.com not easily predictable [1]. Therefore wild mushrooms were easily found in tropical rain forest, lowland or mountainous.

Ranupani Village is located in south area of Bromo Tengger Semeru National Park, East Java, Indonesia. It's nearby the Mount Semeru which has the highest peak of Java Island $(3,676$ $\mathrm{m}$ asl). Elevation of Ranupani itself is on \pm 2000 $\mathrm{m}$ asl. Annual precipitation is $992 \mathrm{~mm} /$ year. There were 1289 habitant in 380 house hold. The ecosystem of this area was included in Mountain 
Zone, which have especially pioneer species such as Casuarina junghubniana. There were also Albiæia sp. and edelweiss as native species. The ground composited most of volcanoes sand from Semeru [2].

The needs of village residents of Ranupani, Lumajang, East Java, for agricultural and residential areas will be met with the services ability of forest ecosystems, especially mountainous area of Bromo Tengger Semeru National Park (TNBTS) for many years. These tropical mountainous forest ecosystems support the growth of wild mushrooms. This wild mushrooms mostly used by local people who live nearby these forests for medication or mostly for alternative of food source. One of these benefits that can be taken by residents of the TNBTS forest area but has not been much studied is the edible mushroom. By the boundaries of TNBTS regulations and local wisdom of Tenggerese, edible mushrooms could become alternative food source in Ranupani if it's explored further. Therefore it is necessary to study ediblemushrooms by ethnobiological approach. This study was conducted to know Ranupani's residents perception of edible mushrooms and its potential as an alternative source of food based on local knowledge and local wisdom of Tenggerese.

\section{MATERIAL AND METHODS}

This study was conducted in NovemberDecember 2011 in Ranupani Village, Lumajang, East Java. Key person and residents of Ranupani were interviewed by semi-structured methods, supported by local translator. In total, 12 people were interviewed, 8 key persons and 4 residents. Respondents were selected by purpose sampling related to the using of the edible mushrooms. Index of Cultural Significance (ICS) was used to evaluate the importance of non-wood forest's yields for local people [3]. Identification of edible mushrooms was based on Guidelines of Flora Diversity Data Collection [2].

$$
\operatorname{ICS}=\sum_{\mathrm{i}=1}^{\mathrm{n}}(\mathrm{q} \times \mathrm{x} \quad \mathrm{i} \quad \mathrm{e})_{\mathrm{ni}}
$$

Where $\mathbf{i}=$ intensity value, $\mathbf{q}=$ quality value, and $\mathbf{e}=$ exclusivity value

The Cultural significance (CS) of an organism has been defined as the importance of the role that the organism plays within a particular culture. It has been used in ethnobotanical research that was also suitable for edible mushroom in lexical retention; to predict changes in the content of folk biological classifications, to asses the significance of a class of resource on the basis of its nomenclatural elaboration; historical and archeological studies of human ecology and subsistence strategies; perceptual salience of organisms; and the borrowing of folk names, products and information about plants between cultures [4].

This study was focus on the three edible mushrooms which are eaten mostly by the villagers, i.e. Pleurotus sp., Clytocybe nebularis and Auricularia auricula which were known by local name Jamur Pasang, Jamur Barat and Jamur Kuping, respectively. Data were analyzed quantitatively descriptive. The expected result is the Ranupani residents' perception of edible mushrooms and its potential as an alternative source of food based on local knowledge and local wisdom of Tenggerese.

\section{RESULT AND DISCUSSION}

\section{The Preference of Edible Mushrooms}

Identified species of the three edible mushrooms were eaten mostly in Ranupani Village are Pleurotus sp., Clytocybe nebularis and Auricularia auricula which were known by local name Pasang, Barat and Kuping, respectively (Figure 1). Pleurotus sp. has the highest preference and intensity to consumed with 3,2 ICS. It means culturally, this edible mushroom were not too important but intensively used as a secondary food sources such as soup (added or sauted), chips (dried) and fried. Ranupani Villagers always consumed edible mushrooms in rainy season (Figure 2).
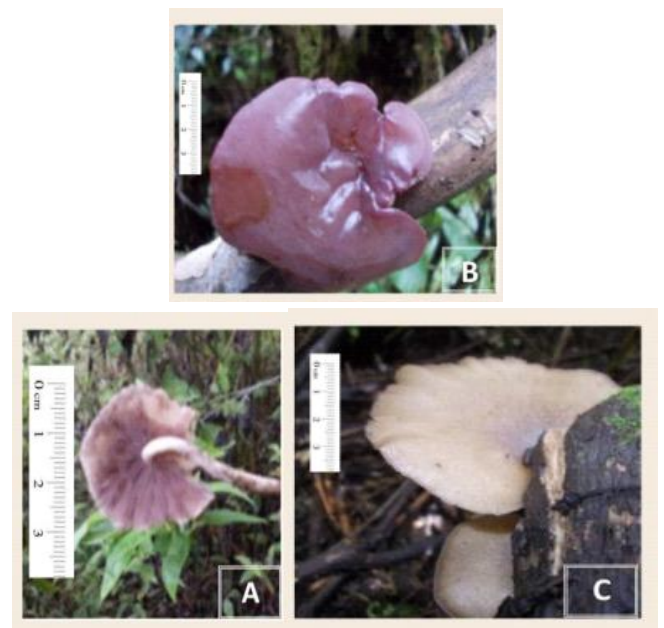

Figure 1. Three edible mushrooms were eaten mostly in Ranupani Village are Pleurotus sp. (A), Clytocybe nebularis (B) and Auricularia auricula (C) which 
were known by local name Jamur Pasang, Jamur Barat and Jamur Kuping, respectively

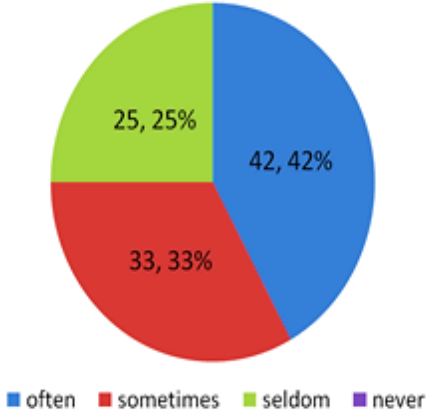

Figure 2. The use intensity of edible mushrooms in Ranupani Village

\section{Local Knowledge and Local Wisdom}

The ability of residents to distinguish edible mushrooms are equal to the searching ability to find edible mushroom substrate (Fig. 3). The residents will recognized the substrate of edible mushrooms on dead trunks of Pasang Tree (Lithocarpus sundaicus), Danglu (Engelhardia spicata), Kemlandingan (Albizia Montana), Casuarina (Casuarina jungbubniana) and Acacia (Acacia decurens). Residents who do not have the ability to distinguish and searching were consumer, get the edible mushrooms by buying from the searcher or distributor for the following packing (Table 1). Collecting and selling edible wild mushrooms by local tribes were also observed in Kohima, India by the Nagaland Tribes. Pleorotus sp. also becomes the most preferable edible mushrooms. It caused by its adapting ability to grow easily on many substrates and easy cultivation [4].

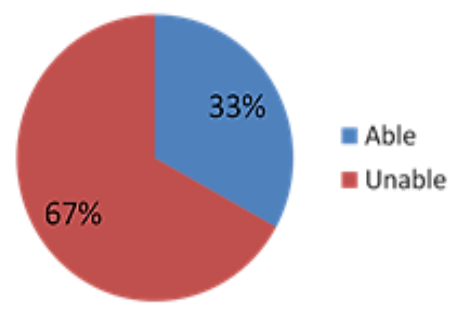

Figure 3. The ability of Ranupani residents to distinguish and searching the edible mushroom

Edible mushrooms searcher have local knowledge to distinguish the edible one. The characteristics of an edible mushrooms are a discrete soft flesh of the fruit body, dark color, no ring on the stipe, the presence of insects (e.g. moths) in the lamellae) and the type of mushroom substrate. There were also assisted growths of wild mushrooms by the residents' raw chop the dead tree trunk as a substrate deliberately. Respondents who knew the time of harvesting edible mushroom are 58.3\%. Pasang mushrooms (natural \& assisted growth) can be found throughout the rainy season, with an interval of 12 days for subsequent retrieval. While Barat and Kuping mushrooms are found throughout the rainy season, but randomly distributed in the forest.

Table 1. Packing and Price of the edible mushrooms

\begin{tabular}{ll}
\hline Packs & Price (IDR) \\
\hline 1 small packs $(1 / 4 \mathrm{~kg})$ & $6,000-8,000$ \\
$1 \mathrm{~kg}$ of wet weight & $20,000-25,000$ \\
$1 \mathrm{~kg}$ of dry weight* & $100,000-300,000$ \\
\hline$*$ exported to the near city &
\end{tabular}

There were unwritten but spoken hereditary local wisdom for the sustainable of the edible mushrooms in Tengger. Only Tenggerese allowed collecting and selling the edible mushrooms in Tengger area to the Tenggerese themselves and tourist (local or foreign). This wisdom is supported by TNBTS regulation that the edible mushroom were not allowed exported out of TNBTS area.

\section{CONCLUSION}

The perception of Ranupani residents on edible mushrooms as an alternative source of food are based on their local knowledge and local wisdom. The three edible mushrooms were eaten mostly in Ranupani Village are Pleurotus sp., Clytocybe nebularis and Auricularia auricula which were known by local name Pasang, Barat and Kuping, respectively. Pleurotus sp. has the highest preference and intensity to consume. The ability of residents to distinguish edible mushrooms and the searching ability to find edible mushroom substrate are equal. Residents who do not have the ability to distinguish and searching were consumer, get the edible mushrooms by buying from the searcher or distributor in packs. There were unwritten but spoken hereditary local wisdom for the sustainable of the edible mushrooms in Tengger. This wisdom is supported by TNBTS regulation. This wisdom expectedly makes sure that the edible mushrooms should be sustained in the forest.

\section{ACKNOWLEDGMENTS}

We would like to express a sincerely gratitude to Ranupani's Villagers for the information in this study and Purnomo S.Si., Laboratory of Ecology and Animal Diversity, Brawijaya for supporting and translating in this study's 
interview. Sincerely thanks were also conveyed to those who help us a lot in the fields.

\section{REFERENCES}

1. Rugayah E, A Widjaja, Praptiwi (2004) Guidelines of Flora Diversity Data Collection. Research Center for Biology. Indonesian Institute of Sciences. Bogor.

2. Departemen Kehutanan Taman Nasional Bromo Tengger Semeru (2010) Bromo Tengger Semeru National Park. http://www.dephut.go.id/ INFORMASI/TN\%20INDO-ENGLISH/

tn_bromo.htm.

3. Turner NJ (1974) Plant taxonomic systems and ethnobotany of three contemporary indian groups of the pacific northwest (Haida, Bella Coola, and Lillooet). Syesis. 7(Suppl 1).

4. Garibay-Orijel R, J Caballero, A Estrada-Torres, J Cifuentes (2007) Understanding cultural significance, the edible mushrooms case. J of Ethnobiology \& Ethnomedicine. 3(4): 10-18.

5. Bhaben T, G Lisha, SG Chandra (2011) Wild edible fungal resources by ethnic tribes of Nagaland, India. J of Traditional Knowledge. 10 (3): 512-515. 